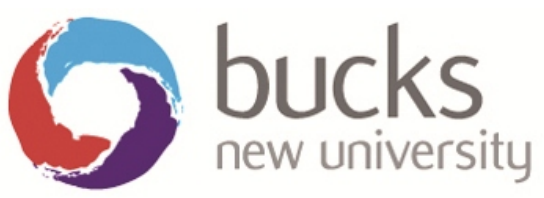

This is the peer reviewed version of the following article:

Adrian Guachalla, (2017) "Social inclusion and audience development at the Royal Opera House: a tourist perspective", International Journal of Culture, Tourism and Hospitality Research, Vol. 11 Issue: 3, pp.436-449, published in final form at:

https://doi.org/10.1108/IJCTHR-07-2016-0071

This article may be used for non-commercial purposes in accordance with Emerald Publishing Limited Terms and Conditions for Use of Self-Archived Versions. 


\title{
Social inclusion and audience development at the Royal Opera House: A tourist perspective
}

\author{
Adrian Guachalla
}

\section{Introduction}

The significance of cultural providers in the context of tourism development has been studied by evaluating the role of museums in a destination's cultural landscape (Grodach, 2008; Franklin, 2016) and the use of opera houses in urban regeneration and destination branding (Colbert, 2003; Smith and Von Krogh Strand, 2010). However, these studies tend to focus on the visual and spatial rather than the functional as the topic of audience development for theatre within a tourism framework remains widely under researched. This paper aims to address this gap in knowledge by focusing on social inclusion and audience development schemes currently used at the Royal Opera House that play a role in the tourist's perception and experience of Covent Garden which is a notorious area in London's urban landscape and a popular precinct for tourism also known as 'Theatreland'.

The notion of social inclusion is defined by Donnelly and Coakley (2002:2) as 'the social process through which the skills, talents, and capacities of individuals are developed and enhanced so that all are given the opportunity to realize their full potential, and to fully participate in the social and economic mainstream'. This suggests that by enabling different mechanisms to recognise and include previously excluded members of society, they in turn become assets through these developmental processes as they seek to participate and contribute economically to activities that were not originally pursued. In this sense, the economic contribution to cultural activities from tourists that were not previously interested in attending opera or ballet performances is catalysed after they have been granted the opportunity to learn and be engaged by these cultural products (see Oxoby, 2009). Supporting this, Sharp et al. (2005) highlight this important link by noting the relationship between social inclusion and urban economic competitiveness. This is achieved as destinations engage a growing market of groups and individuals with their cultural produce adding value to the quality of experiences that tourists gain from their visits to these destinations (Marcuse and van Kempen, 2002). It is therefore clear that the economic sustainability of cultural institutions is inextricably linked to the pursuit of new and emerging markets which effectively leads to an improvement on their corporate image and public perception (Sandell, 1998). Coffee (2008) contributes to these frameworks by noting the formative nature of social inclusion initiatives implemented by museums that provide novel and active experiences to new users (Smith, 2007) that can potentially become influential stakeholders in the future (also supported by Oxoby, 2009). It should be noted, however, that museums and theatres face different challenges related to carrying capacity and provide a contrasting set of experiences to their visitors as performing arts are inclined to put the user in a passive role. This legitimises the need to conduct research on the different tools that are used by performing arts institutions to develop their new audiences. In view of this, this paper aims to evaluate the effectiveness of these initiatives as implemented by the Royal Opera House in Covent Garden and their impact on the tourist's perception and experiences of the area where it is set. 


\section{Literature review}

Urban developments such as museums, theatres and other commercial venues can help shape the social, cultural and visual landscapes of a tourist destination (Wing Tai Wai, 2004). However, arts consumption patterns are important to consider as an Opera House's cultural produce (high arts) tends to be consumed by a select group of people. Younger generations along with the lower socio-economic stratum of society have been identified as vulnerable to exclusion and the arts can be used to offset this effect (Karkou and Glasman, 2004). In this sense, a theatre's limited carrying capacity imposes challenges that other providers of culture such as museums are free from in terms of developing audiences and facilitating social inclusion (Sandell, 1998). Given these considerations and to address the overall aim of this study, the conceptual framework presented below discusses the topics of cultural capital, social inclusion, audience development, social capital and different approaches to categorising the cultural tourist.

\section{Cultural consumption and performing arts}

Tourists that expand the range of cultural events they engage with can be related to the notion of cultural capital acquisition, defined by Honneth (1986:58) as 'all the learnable skills and competencies that enable individuals to handle the social potentials of scientific information, aesthetic enjoyment and everyday pleasures'. The author makes reference to Bourdieu (1983) who identifies embodied cultural capital resulting in the acquisition of new knowledge and dispositions that are learned through engagement with and participation in cultural activities. These can be associated with attendance to performing arts events that enable information acquisition of performers, cultural venues and other details of cultural productions. Bourdieu (1984) also highlights the role of cultural intermediaries that difuse 'cultural attitudes and the aesthetics of lifestyle into the mainstream' (as stated by Nancarrow et al 2001:312). In this sense, the role of cultural providers such as Opera Houses and their initiatives to make their cultural produce accessible to new and emerging markets can be fundamental in the process of cultural capital acquisition. This process leads to strengthened networks and bonds among groups and individuals in society leading to social cohesion (Maloutas and Pantelidou, 2004) which in turn reflects the development of social capital (OECD, 2001). The OECD (2001) highlights the different approaches that can be applied in the task of defining social capital (see Putnam, 2000; Grafton, 2005; Ostrom, 2000) and conceptualises it as 'networks together with shared norms, values and understandings that facilitate co-operation within or among groups' (p. 41). Adding to this debate, Woolcock (2001) identifies vertical linkages between different layers of the social ladder as a form of social capital that is the result of social cohesion. This can be illustrated in the performing arts context when specific groups commonly seen as excluded from cultural products (DiMaggio and Usseem, 1978; Belfiore, 2002) are given the opportunity to engage with high culture, acquire cultural capital leading to social cohesion that is cemented in social capital. This framework is approached by McCabe et al. (2010) who find a strong link between participation driven by inclusion strategies and an enhancement in the tourist's experience of objects and places (also discussed in a tourism context by Botterill and Klemm, 2005). Therefore, it is clear that the benefits of building bridges towards new markets for the performing arts ensures the long term economic sustainability of cultural institutions while making active contributions to social networks and interactions within society (see Aitchison, 2007).

In the performing arts context, DiMaggio and Useem (1978) propose that arts appreciation is trained and contextual, that it indeed enhances class cohesion and closely relates to cultural capital acquisition. The authors (p.142) indicate that "adult political attitudes are shaped by the family during childhood and 
adolescence. This intergenerational reproduction of cultural interests is likely to extend to aesthetic tastes as well". They argue that an individual's personal background that roots down to their childhood will underpin their personal preferences in their adult life (supported by Timothy, 1998). However, appreciation for certain art forms can also be acquired if the individual is exposed and cultivated until they develop enthusiasm and interest in participating in cultural endeavours. The authors include the contextual dimension of appreciation for the performing arts which can be related to tangible elements of the event's experience such as the venue itself. But from a more complex perspective, to intangible elements such as the social interactions that take place and the social make-up of the audience for example. DiMaggio and Useem (1978) not only refer to education as the individual's highest educational attainment and refute the notion that a person "lacking either appropriate family background or educational experiences remains deprived of the means for appropriating the high arts throughout their lives” (p.149). But they also argue that exposure to the arts is associated with income levels as these tend to be expensive to access and exclusive to those who can afford them (see Kawashima, 2000). Further supporting this, Belfiore (2002) argues that these forms of high arts are subject to high standards of quality of productions, and consequently, access to them tend to be restricted to the upper classes that can pay the high price of admission, which itself relates to the high cost of staging these productions.

\section{Whose House is this?}

Adding to these debates, it is important to consider that Opera Houses and other major providers of culture are subject to public subsidy (Belfiore, 2002) raising issues

concerning their restricted access to those that can afford it. The author (p. 92) highlights that "within the British arts sector, the actual exclusion of large sections of the population (mainly belonging to the working class) from publicly funded arts activities has been a source of concern”. She also refers to the Arts Council's Royal Charter (1967), which emphasises its obligation to make the arts more accessible across social classes in the country. These frameworks are still current in the present day as the Arts Council England's remit (2015) clearly has education, social inclusion, audience development and related elements to social equity at its core. Therefore, the issue of audience development acquires two dimensions: the first relates to the urge of developing new audiences to ensure the future production and consumption of the arts by succeeding generations. The second relates to equal distribution of cultural wealth. Although these cultural attractions are primarily developed for local communities (Richards, 2007) as a result of a post-industrial trend towards leisure (Parker, 1976), there is a strong link between

the residing community, the domestic tourist market and overseas international visitors to accomplish the 'flagship effect' noted by Wing Tai Wai (2004) and Franklin (2016).

Audience development in the context of theatre has been widely researched (see Lindelof and Hansen, 2015; Scollen, 2009; Hansen, 2015; Reason, 2015) but the tourist theatre audience and how to develop it remains an area that continues to be neglected by current studies. Regardless of this, Kawashima (2006) proposes four types of audience development as follows:

- Extended marketing: It targets potential and lapsed (not frequent) attendees. It does not alter the cultural product, but uses it to tailor marketing strategies to draw attention to it and raise attendance by occasional or potential attendees. The purpose is financial and artistic (when for example, a new opera is promoted in different sectors of society) and can be related to Rentschler's (2002) approach on marketing the arts.

- Taste cultivation: these initiatives target existing audiences and do not alter the cultural product either but focus on expanding the portfolio of similar products. For example, when there is demand for a particular ballet production but efforts are made to promote attendance to 
comparable productions. The purpose is artistic, financial and educational (see Levy-Garboua and Montmarquette, 2002 in Towse, 2013).

- Audience education: akin to taste cultivation initiatives, these target existing audiences as well but aim to provide attendees with a deeper insight of the cultural product. For example, when an opera is preceded by a discussion of its background and content to enhance the audience's understanding of it for educational, and to an extent, financial purposes (see Prendergast, 2004).

- Outreach: These initiatives target people who are unlikely to attend cultural events (from deprived communities for example). They take the form of arts projects which tend to be participatory in line with Smith's (2007) notion of novel forms of cultural tourism providing active experiences to its users. The purpose is social and relates to equal distribution of cultural wealth as indicated above.

\section{The cultural tourist}

The frameworks above are useful in the understanding of the different phases involved in the task of developing audiences for the arts and the array of elements that influence these processes. However, it is also important to contextualise them within a tourist grounding. Across most studies in cultural tourism, levels of motivation and nature of experiences emerge as salient factors. Such is the case of McKercher's (2002) approach to categorising cultural tourists: firstly; incidental, casual and sightseeing tourists with shallow engagement with cultural products but with rising levels of cultural motivation. Secondly, serendipitous and purposeful cultural tourists both of which have deeper experiences of culture but differing levels of cultural motivation. Similarly, Hughes (2000) indicates that tourists can either be artscore when the objective of their travels is to undertake cultural tourism in the form of performing arts, or arts-peripheral when these activities complement another primary travel purpose. The author asserts that primary arts-core tourists are understood as visitors whose sole purpose of visit is to undertake cultural tourism; or multi-primary and arts-core when performing arts are part of the main objectives of travel. Likewise, the arts-peripheral tourist can be either incidental when undertaking cultural activities is not the objective of the visit to a destination but there is a willingness to engage with culture or accidental when this happens spontaneously. These contributions unravel the different angles under which the cultural tourist can be analysed but few of these categories take into account the "unsuspecting" potential cultural tourists confirming that this is an emerging area of study in need of further empirical evidence and scientific discourse. Furthermore, the meaning assigned to cultural products is an important issue to consider as Richards (1996) argues that these meanings will be the key determinants of the nature of a tourist's experience (see Urry, 1990; MacCannell, 1999). This indicates the need of a flexible methodological approach and has been taken into account when designing the data collection tool for this study as discussed below.

\section{Research approach and design}

This study adopts a case study approach as it focuses on the role that a specific major provider of culture plays in the engagement of new tourism audiences for opera and ballet. Case study research is evaluated in-depth by Yin (2013) who identifies a range of benefits of conducting case study-based research as it enables the discovery of new knowledge applied to a specific context adding deeper conceptual layers to general theories and hypotheses. Given these considerations and in view of the nature of this research, a case study-based approach was identified as an adequate means to contextualise the study of the Royal Opera House in Covent Garden and its audience development initiatives leading to social cohesion and social capital. 
The Royal Opera House is firmly established at the core of London's Covent Garden as the UK's leading provider of opera and ballet productions. It was subjected to a $£ 213 \mathrm{~m}$ redevelopment scheme between 1997 and 1999 which aimed to improve its infrastructure and physical appearance leading to an attractive façade in line with current trends in urban developments (Dixon in BBC, 1999). Its main entrance however, does not face the popular market place within the area leading to perceptions that the House is 'hidden' amidst the sights and sound of Covent Garden. Its redevelopment was not only infrastructural; it also propelled a shift in the institution's values in terms of target markets and intended audiences. As expressed by Jones (2002), the new layout integrates patrons from the stalls with amphitheatre ticket holders: 'the aim is to encourage the audience to move up as well as down (...) reversing the sense of social hierarchy that existed within the old House' as cited in Latham and Swenarton (2002:112) (see Waterton et al., 2006 for the challenges of enabling social inclusion at cultural attractions). This highlights the way in which the House's 'excellence, access and artistic development' creed is put to practice, indicating that indeed, access initiatives are implemented in the House's operations (see Mosse, 1995). The House's focus on indiscriminate access for all audiences is evident in its student stand-by scheme that releases tickets at lower prices for students and ultimately, in the fact that the House can be visited by anyone, free of charge, during designated times where visitors are welcome to the front of house foyers and have access to the restaurants, bars, terrace and exhibition spaces (Tooley, 1999). The House's Learning and Participation Unit 'aims to inspire and empower people to learn and develop creative skills through engagement with its work and art forms' (ROH, 2016). These initiatives also include backstage tours, insight evenings and the live projection of current productions in popular tourist areas across the country engaging over 41000 people in 2015 (BP, 2016). This focus raises questions on its impact on the tourist market and this study presents findings on the influence it has on the tourist's perception and experience of Covent Garden - the area where it is set. However, it is also important to note that the degree to which the Opera House has the potential of engaging new audiences is also dependent on a number of variables intrinsic to each individual. For this reason, it was important to adopt a flexible methodological approach that focuses on how each person perceives reality and the different subjective influences that shape these processes as discussed below.

\section{Methodology}

According to Denzin and Lincoln (2005:185) a constructivist research approach implies the 'production of reconstructed understandings of the social world (...) (and that) constructivists value traditional knowledge, connect action to praxis and build on anti-foundational arguments while encouraging experimental and multi-voiced text'. Because no general assumptions can be made about the role of the Royal Opera House on the tourists' perception and experience of Covent Garden or the effectiveness of its audience development schemes, it is important to adopt this non-foundational approach that provides the flexible framework required to enquire individually and understand subjective realities (Quinn Patton, 2004; Bryman, 2004). Thus, a social constructivist approach was adopted to conduct this study in line with Gill (2000) who asserts that this perspective implies 'a critical stance towards taken-for-granted knowledge and scepticism towards the view that our observations of the world unproblematically yield its true nature to us' (as cited by Bauer and Gaskell, 2000:173).

\section{Method}

Given the non-foundational perspective adopted to conduct this study, it was clear that a flexible data collection tool was needed to capture rich and wide ranging data. For this reason, semi-structured interviews were chosen as the most suitable method as they suitably respond to this need (Arksey and Knight, 1999; Finn et al., 2000). Covent Garden is an area that attracts a wide array of visitors and hence, 
a convenience sampling approach was adopted responding to Smith's (2010) recommendations on tourism studies of this scope. In order to assess the significance of the Opera House to the area's visitors, 213 interviews were conducted throughout six locations within the Covent Garden area. These were followed by 93 interviews with tourists inside the theatre who were not attending a performance but were in the building as daytime visitors. In spite of the high number of interviews conducted, the quality of the data captured was not equally substantial. This is evident in the fact that some interviews lasted for up to 45 minutes in cases when interviewees expanded and developed their views in length. Whereas other interviews concluded after 3 minutes when tourists did not have the willingness to further develop their views or had no more views to share.

Both international, domestic, first time and repeat visitors were chosen randomly throughout different times of the day and through the spring and summer months when participant recruitment was successful given the high levels of tourist activity in the area. The topic guide enquired about their perception and experience of the area and whether the Royal Opera House exerted any influence in these processes. The audience development tools that the Royal Opera House uses to engage new audiences resulting in social inclusion were emerging themes as some tourists noted the influence that these initiatives exert in their awareness of the theatre and experience of the area. In this sense, the topic guide explored the interviewees' awareness of the Opera House and whether it plays a role in their perception and experience of Covent Garden. If an interviewee made reference to its daytime openings or live performance relays for example, then further probing questions were asked to further understand how these initiatives succeeded in engaging them. It is important to note that the data presented in this paper focuses exclusively on the topic of audience development and social inclusion initiatives which emerged as important findings given their influence on some tourists' perception and experience of place. But not all interviewees identified these as important issues to consider. In this sense, other findings stemmed from these interviews that were conducted as part of a wider Doctoral study include the role that other tourists play in these processes and the influence of the area's built environment for example (see Guachalla, 2016; Guachalla, 2013). Therefore, this paper's limitations and boundaries are clearly defined by the sharp focus on the work that the Opera House does to develop its audiences and the impact it has on the Covent Garden tourists’ perception and experience of place.

\section{Data analysis}

The interviews conducted were transcribed manually after the data collection stage drew to a close. This data was extensive and Bryman (2004:417) asserts that 'one of the most significant developments in qualitative research in the last twenty years is the emergence of computer software that can assist in the use of qualitative data analyses'. Likewise, Silverman (2000) highlights the advantages of using such software and indicates that it can help the researcher in speeding the process of handling large amounts of data and enhancing the rigor in which the information can be analyzed (also supported by Phelps et al. 2007). For this reason, QSR N*Vivo was used to analyse the interview transcripts in two stages: the first organized the findings in initial categories. These were then reanalyzed leading to a range of findings related to the factors that influence the tourists' perception and experience of Covent Garden and whether the Opera House plays a role in these processes. This reiterative approach is noted by Denscombe (2007) and Arksey and Knight (1999) as good practice in qualitative data analysis and lead to the findings relating to social inclusion and audience development as presented below.

\section{Findings and discussion}


The first section of the interview captured the sample's socio-demographic profile in terms of their age and nationality to understand the type of visitors that the Opera House and the area attract. Out of the 213 interviews randomly conducted in different locations throughout the area other than the Opera House, $87 \%$ were international visitors from all over the world and of these, $72 \%$ were below 40 years of age indicating that the area tends to attract a younger international tourist segment. Conversely, from the 93 interviews conducted inside the Opera House, 71\% were domestic and European visitors and 63\% were over the age of 50 indicating that the flagship attracts an older, domestic and European set of tourists. Regardless of this, many interviewees from both the area and the Opera House evidenced that the social inclusion and audience development initiatives put forward by the theatre influenced to different extents their perception and experience of the area:

"I'm always hoping that any theatre would reach to a large audience, not exactly to their principal audience which at this time they are cultured people that want to see ballet and opera and theatre of that nature, but sometimes it's a very limited crowd. I think once people get into it, they want to see it more (Katrina, US)".

The previous statement highlights the importance of audience development and notes how it can succeed in generating awareness of the cultural offer of an institution and the provision of performing arts. In relation to this and considering the perceived disadvantage that the flagship's physical location imposes on the visual perception of the building, it was evident that the degree to which the interviewees assign importance to the Opera House is often directly associated with whether they have been inside the building or not. This was evident when interviewees were asked if they considered the Opera house to be an important element of the area: "Not to me because I have never been there but I'm sure it is (Anna, Austria)”. In this sense, it is clear that their perception of the Opera House as a building and as an institution directly correlates with previous exposure to its work and facilities. Further supporting this and when asked about their perceptions of the theatre once they visited it, many interviewees expressed that the theatre is largely better perceived and experienced from the inside given its concealed outer appearance. This confirms also confirms the importance of introducing the individual to the inside of the building in order to raise awareness of its significance and relationship with the area:

"I think it's much more powerful on the inside than outside. Outside you don't spot it immediately like La Scala in Milan for example. But inside it's a great place (Ricardo, Italy)”

"Inside it's amazing (...) I think it's a much more internal image I get for when I think of the Opera House than the outside. So I don't think it's visually important to Covent Garden because I think it is quite hidden. (David, UK)”

The Opera House's initiatives to engage a wider audience emerged from the data as some interviewees noted the positive experience provided by their discounted tickets for students, which made a respondent feel 'special' when she was asked about her affective response to audience development initiatives that she engaged with. This was also noted by international visitors that do not have such varied cultural opportunities in their home countries and younger people that are yet to discover these art forms:

"It's something that I haven't gotten into yet. I'd like to be very culturally aware but probably as I age a lot older I will probably get into and go there but at the moment I'm into painting and things like that but it's probably something I will look into (Luke, UK)” 
“I think it's a centre for culture and also for us, as tourists. In Thailand we don't have this much exposure. So coming to metropolitan city like this is a good opportunity for us to see and have a chance to listen and experience Opera Houses (Narn, Thailand)”

Another initiative aimed at social inclusion and increasing cultural awareness is the large scale relay of live performances in high profile public areas throughout the country resulting in the engagement of audiences that would not otherwise be interested in attending an opera or ballet performance. These audience development tools emerged from the data when interviewees were asked about the factors that influence their perception of the Opera House. It should be noted though that outdoor performances take place outside the building and as indicated above, the task of 'bringing people inside' is vital to increase their level of awareness of its presence in the area considering its perceived concealment amidst the area's urban clustering. In relation to this, the House is open to the general public during designated times when they do not require a ticket to go inside and make use of its facilities. This was noted by many interviewees as a positive initiative that is not widely known when asked about the factors that influence their perception of the House:

"I was pleasantly surprised when I found that I didn't need a ticket to come into the Opera House. It's a fantastic piece of architecture and a lovely building (Claude, France)"

"I think it would be quite good if you had a few signs out. Maybe to draw more people in because I think people feel a bit worried about coming in (Roseanne, UK)"

Although some interviewees indicated that the activities that take place on stage is what they regard as the essence of the Opera House, the building's added services and facilities play an important role in the perception and experience of the theatre. When asked about their motivation to visit, some interviewees indicated that they intended to shop at its store, book tickets, make use of its eating and drinking facilities, appreciate the view from its terrace and to attend its exhibitions. This confirms that the experience of the building is not only related to the direct appreciation of performing arts, but also to the provision of these services. In this sense, the experience of being inside the building to make use of any of them is likely to encourage attendance to a performance, which harmonises with the Opera House's policies of social outreach and audience engagement:

"Has your perception of the place changed now that you have been inside the building? Well now I feel like coming to watch a show because it's so pretty, and the decorations, the photos on the exhibition that we just saw... they make you want to come and experience that entire atmosphere live. (Angelica, Mexico)".

Some interviewees recognised that the area's visitors need to be introduced to the work of the Opera House in order for it to exert an influence on their perception and experience of the area. However, this discovery process can also work conversely, with the Opera House's visitors' discovery of the area and its many elements as an unexpected experience (as stated by some interviewees when asked about their perception of the relationship between the area and the theatre). This evidence supports a bilateral, synergic and mutually beneficial relationship between the area and the Opera House as they both feed each other's visitors into one another and provide exposure to each other's tourist products, services and experiences:

"I'm sure a lot of people experience Covent Garden because they come to visit the Royal Opera House. It draws people from around the world. As far as I understand it's a pretty well respected institution so I am sure a lot of people come specifically, those people who are really into opera 
come from all over the world for it and I imagine its reputation spread out further than Covent Garden itself so I imagine that people probably come to visit the Opera House and find Covent Garden a kind of unexpected jewel attached to the side of it (Mike, UK)"'.

Regardless of its popular location, the royal attachment of the institution's name leads many interviewees to perceive the flagship as socially exclusive and elitist. This is further corroborated by high number of interviewees expressing a lack of interest in experiencing high culture. They explained this lack of interest because 'it is not their thing' and to the perceived high cost that attending a performance at the Opera House may imply. These high costs were recognised by some interviewees, who acknowledged that the high quality of the Opera House's productions demands for ticket prices to be expensive (Belfiore, 2002). As a consequence, those seeking leisure activities and relaxing experiences lack the sense of belonging and connectivity with the Opera House (Timothy, 1998). This lack of connectivity along with the building's subtle physical presence in the area prevents them from exploring the theatre in spite of its free daytime openings. The fact that the majority of interviews conducted inhouse belonged to the domestic and older segments of the sample confirms that the Opera House has a stronger appeal to domestic visitors that are of a more mature age. This related to DiMaggio and Ussem's (1978) approach to audience development as arts appreciation is trained and is the result of an educational journey (Kawashima, 2006) that nurtures individuals that connect with and appreciate opera and ballet productions. However, it is also clear that the economic sustainability of these productions would benefit from engaging younger and international tourist audiences which confirms the need to continue implementing initiatives that allow new audiences to acquire these tastes (Aitchison, 2007).

Adding to these challenges is the fact that attending a performance at the Opera House is a passive experience where the audience does not take an active part as opposed to informally watching a street performer, resulting in some of the area's visitors' disregard of the Opera House as an element of their experience of Covent Garden (Smith, 2007). However, open air live relays of opera and ballet performances may result in a more flexible experience that is active and entertaining as identified by Smith (2007) in terms of novel forms of cultural tourism. But tourism development asides, it is important to note that cultural attractions of this nature are primarily intended for a domestic audience (Richards, 2007), which largely explains why the majority of in-house interviewees were British (but tourists nonetheless) and European. Furthermore, they belonged to the older age groups indicating the impending urgency of engaging younger generations necessary to secure the future of the production of opera and ballet. But it could also be asserted that as a person grows older, cultural capital increases leading tourists to be more open to explore a new and more diverse set of art forms (DiMaggio and Ussem, 1978). From a social point of view, the authors note that arts appreciation enhances class cohesion leading to Timothy's (1998) sense of connectivity which can also be interpreted as a sense of belonging. This may not only relate to the Opera House itself as an institution but to a sense of belonging to the new generation of younger audiences that have acquired cultural capital (Honneth; 1986; Nancarrow et al 2001) through social inclusion initiatives. This in turn provides a platform for social cohesion among an emerging market of tourists that have been exposed to the institution's work (Botterill and Klemm, 2005; Aitchison, 2007). As a result, the base of social capital is strengthened (Woolcock, 2001) which ensures the long term economic and social sustainability of the theatre and of its productions (OECD, 2001).

\section{Conclusions}

The Opera House's response to perceptions of exclusivity through access initiatives and audience engagement schemes emerged from the data as an important topic as many interviewees noted that their 
perception of the institution is influenced by them. Some of the most notable examples are the live relay of performances in public areas, discounted tickets for students and its daytime access to free exhibitions and a terrace café in line with Kawashima's (2006) extended marketing, taste cultivation, audience education and outreach framework. Furthermore, the Opera House is largely subsidised by public funds, which means the institution has a social responsibility to make its products accessible to a wide range of markets. As a result, Botterill and Klemm's (2005) and McCabe et al's. (2010) notions on social inclusion in a tourism context have been identified as tourists benefit from audience development schemes that enhance their cultural capital strengthening their social bonds and fostering social capital. Active experiences for diverse audiences are important for the development of cultural tourism markets (Smith, 2007) and they can be associated with the initiatives listed above as they not only entail the passive experience of watching a performance. They invite the user to play an active role in the discovery of the Opera House by for example attending an open air live relay of a production or discovering the theatre's front of house areas as daytime visitors. But it is up to the individual to explore these opportunities, which depends directly on their level of cultural motivation (McKercher, 2002) and inquisitive approach to a tourist's experience of a precinct (Hayllar et al, 2008). The building's subtle physical presence prevents some of the area's visitors from being aware of these opportunities as noted by many interviewees. But potential new audiences can be provided with welcoming feelings of belonging (Timothy, 1998) that might result in novel markets for the appreciation of opera and ballet. In view of this, further studies on this subject could focus more specifically on the emotional and affective states that audience development initiatives catalyse among recipients. From an international tourism perspective, future research could explore how an individual's socio-demographic characteristics including cultural background and nationality influence their engagement with opera and ballet productions.

An Opera House may exert an influence over a visitor's perception and experience of place when it presents itself in a visually stimulating manner relating to DiMaggio and Useem's (1978) stance on the contextual nature of arts appreciation. In addition to this stimulus, added facilities such as shops, cafes and terraces can potentially engage the area's visitors and embed the Opera House as part of the overall experience of the urban precinct. However, the wide assortment of experiential opportunities in an environmentally clustered urban precinct such as Covent Garden causes it to remain hidden from the area's visitors' reach depending on their levels of cultural motivation (McKercher, 2002; Hughes, 2000, Richards, 1996). Therefore and in terms of managerial implications, the Learning and Participation Unit's work at the Royal Opera House continue to be faced with the challenge of the perceived visual concealment of the building within an area that provides a range of experiential opportunities for tourists. Hence an emphasis on the core of the theatre's work - its productions and heritage - should remain at the forefront of its social inclusion and audience development initiatives. Notwithstanding the physical attributes and facilities of the building that have also been noted as attractive assets that engage tourists once they discover them. In a sense, the Opera House's relative concealment in a popular area for tourism may be regarded as part of its appeal to domestic and older visitors likely to seek culture, as they see it as a 'hidden gem' of Covent Garden. In a way, it provides a space and a platform that is free of perceived 'tourist' activities such as street busking, shopping, eating or drinking for example, all of which are widely regarded as typical of Covent Garden. However, audience development initiatives like the House's daytime openings and live relays of current productions play an important role in the engagement of tourist markets. These are needed as they can also make important financial contributions towards the House's future productions and ensure their long-term sustainability. This confirms that they are an important element of the social capital base needed to support its operations and ultimately, they further strengthen a reciprocal and synergic relationship between Covent Garden and the Royal Opera 
House.

\section{References}

- Aitchison C.C. (2007) Marking difference or making a difference: Constructing places, policies and knowledge of inclusion, exclusion and social justice in leisure, sport and tourism. The critical turn in tourism studies: Innovative research methodologies. Pages 77 -90

- Arksey H. and Knight H. (1999) Interviewing for Social Scientists. London: SAGE

- Arts Council England (2015) Great Art and Culture for Everyone: 10 year strategic framework 2010 - 2020. $2^{\text {nd }}$ Edition. [online] Available from: http://www.artscouncil.org.uk/sites/default/files/downloadfile/Great_art_and_culture_for_everyone.pdf [Accessed: 08 July 2016]

- Belfiore E. (2002) Arts as a means of alleviating social exclusion: Does it really work? A critique of instrumental cultural policies and social impact studies in the UK. International Journal of Cultural Policy. Volume 8 Issue 1. Pages 91 - 106

- Bauer M. and Gaskell G. (2000) Qualitative Researching: with Text, Image and Sound, A Practical Handbook. London: Sage

- Botterill D. and Klemm M. (2005) Tourism and social inclusion. Tourism Culture \& Communication. Volume 6 Issue 1. Pages $1-62$

- Bryman A. (2004) Social Research Methods. Second Edition. Oxford University Press: Oxford

- BBC (1999) The Official BBC Guide to the Reopening of the Royal Opera House. BBC: London

- Bourdieu P. (1983) The Field of Cultural Production. Cambridge: Polity.

- Bourdieu P. (1984, 1986) Distinction: A Social Critique of the Judgment of Taste, trans. R. Nice. London: Routledge \& Kegan Paul.

- BP (2016) Connecting through arts and culture: BP and the Royal Opera House. [Online] Available from: http://www.bp.com/en_gb/united-kingdom/bp-in-the-community/connectingthrough-arts-and-culture/bp-and-the-royal-opera-house.html [Accessed: 13 March 2016]

- Coffee K. (2008) Cultural inclusion, exclusion and the formative roles of museums. Museum Management and Curatorship. Volume 23 Issue 3. Pages 261 - 279

- Colbert F. (2003) The Sydney Opera House: An Australian icon. International Journal of Arts Management Volume 5 Issue 2. Pages 69 - 77

- Denscombe M. (2007) The Good Research Guide. Buckingham: Open University Press

- Denzin N. and Lincoln Y. (2003) Collecting and Interpreting Qualitative Materials. Second Edition. London: Sage

- DiMaggio P. and Useem M. (1978) Social Class and Arts Consumption: The Origins and Consequences of Class: Differences in Exposure to the Arts in America. Theory and Society. Volume 5 Number 2. Pages 141 - 161

- Donnelly,P. and Coakley J.J. (2002) The role of recreation in promoting social inclusion. Toronto: Laidlaw FoundationHayllar B., Griffin T. and Edwards D. (2008) City Spaces Tourist Places: Urban Tourism Precincts. Oxford: Butterworth-Heinemann

- Finn M., Elliot-White M. and Walton M., (2000) Tourism and Leisure Research Methods: Data Collection, Analysis and Interpretation. Essex: Pearson Education

- Franklin, A. (2016) Journeys to the Guggenheim Museum Bilbao: Towards a revised Bilbao Effect. Annals of Tourism Research. Volume 59. Pages 79 - 92 
- Grafton R. (2005) Social Capital and fisheries governance. Ocean and Coastal Management. Volume 48. Pages $753-766$

- Grodach C. (2008) Looking beyond image and tourism: The role of flagship cultural projects in local arts development. Planning, Practice and Research. Volume 23 Issue 4. Pages 495 - 516

- Guachalla A. (2016) Perception and experience of urban areas for cultural tourism: A social constructivist approach in Covent Garden. Tourism and Hospitality Research. p.1467358416646820

- Guachalla A. (2013) The Role of Cultural Flagships in the Perception and Experience of Urban Areas for Tourism and Culture. Case Study: The Royal Opera House in Covent Garden. European Journal for Tourism Research. Issue 6 Volume 1. Pages 83 - 88

- Hansen L.E. (2015) Behaviour and attitude: the Theatre Talks method as audience development. International Journal of Cultural Policy. Volume 21 Issue 3. Pages.344 - 359

- Honneth A. (1986) Fragmented world of symbolic forms: reflections on Pierre Bourdieu's sociology of culture. Theory, Culture and Society. Volume 3. Pages 55 - 69

- Hughes H. (2000) Arts, Entertainment and Tourism. Oxford: Butterworth-Heinemann

- Kawashima N. (2006) Audience Development and Social Inclusion in Britain. International Journal of Cultural Policy. Volume 12 Issue 1. Pages 55 - 72

- Kawashima N. (2000) Beyond the division of attenders vs. non-attenders : a study into audience development in policy and practice. Working Paper. Coventry: University of Warwick. Centre for Cultural Policy Studies. Research papers, Vol.6

- Karkou, V. and Glasman, J. (2004) Arts, education and society: the role of the arts in promoting the emotional wellbeing and social inclusion of young people. Support for learning. Volume 19 Issue 2. Pages 57 - 65

- Latham I. and Swenarton A. (2002) Dixon Jones: Buildings and Projects 1959-2002. London: Right Angle Publishing

- Lindelof A.M. and Hansen L.E. (2015) Talking about theatre: Audience development through dialogue. Journal of Audience \& Reception Studies. Volume 12 Issue 1. Pages 234 - 253

- McKercher B. (2002) Towards a Classification of Cultural Tourists. International Journal of Tourism Research. Volume 4. Pages 29 - 38

- MacCannell D. (1999) The Tourist: A New Theory of the Leisure Class. London: University of California Press

- Maloutas T. and Pantelidou M. (2004). The glass menagerie of urban governance and social cohesion: Concepts and stakes/concepts as stakes. International Journal of Urban and Regional Research. Volume 28 Issue 2. Pages 49-65

- Marcuse P. and Kempen R. (Eds) (2002) Of States and Cities: The Partitioning of Urban Space. Oxford: Oxford University Press

- McCabe S., Joldersma T. and Li C. (2010) Understanding the benefits of social tourism: Linking participation to subjective well-being and quality of life. International Journal of Tourism Research. Volume 12 Issue 6. Pages 761 - 773

- Mosse K. (1995) The House: Inside the Royal Opera House, Covent Garden. London: BBC Books

- Nancarrow C., Nancarrow P. and Page J. (2001) An Analysis of the Concept of cool and its marketing implications. Journal of Consumer Behaviour. Volume 1 Issue 4. Pages 311 - 322

- OECD (2001) The Well-being of Nations: The Role of Human and Social Capital. Paris: OECD Publishing 
- Ostrom E. (2000) Social capital: a fad or a fundamental concept?” in Dasgupta, P. and Serageldin, I. (eds.) Social Capital: A Multifaceted Perspective. Washington, D.C: The World Bank

- Oxoby R. (2009) Understanding social inclusion, social cohesion, and social capital. International Journal of Social Economics. Volume 36 Issue 12. Pages 1133 - 1152

- Quinn Patton M. (2002) Qualitative Research and Evaluation Methods. London: Sage

- Parker S. (1976) The Sociology of Leisure. Plymouth: George Allen \& Unwin

- Phelps R. Fisher K. and Ellis A. (2007) Organizing and Managing your Research; A Practical Guide for Postgraduates. London: SAGE

- Putnam R. (2000) Bowling Alone: The Collapse and Revival of American Community. New York: Simon and Schuster

- Reason M. (2015) Participations on participation: researching the active theatre audience. Journal of Audience \& Reception Studies. Volume 12 Issue 1. Pages 271-280

- Rentschler R. (2002) Museum and performing arts marketing: The age of discovery. The Journal of Arts Management, Law, and Society. Volume 32 Issue 1. Pages 7 - 14

- Richards G. (1996) Production and Consumption of European Cultural Tourism. Annals of Tourism Research, Volume 23 Number 2. Pages 261 - 283

- Richards G. (2007) Cultural Tourism: Global and Local Perspectives. New York: Haworth Hospitality Press

- Royal Opera House (2016). ROH Learning \& Participation. [online] Available from: < http://www.roh.org.uk> [Accessed: 25 June 2016]

- Sandell R. (1998) Museums as agents of social inclusion. Museum management and curatorship. Volume 17 Issue 4. Pages 401 - 418

- Scollen R. (2009) Talking theatre is more than a test drive: two audience development methodologies under review. International journal of arts management. Volume 12 Number 1. Pages $4-13$

- Sharp J., Pollock V. and Paddison, R. (2005). Just art for a just city: public art and social inclusion in urban regeneration. Urban Studies. Volume 42 Issues 5 - 6. Pages $1001-1023$

- Silverman D. (2000) Doing Qualitative Research: A Practical Handbook. London: Sage

- Smith A. and von Krogh Strand I. (2011) Oslo’s new opera house: Cultural flagship, regeneration tool or destination icon? European Urban and Regional Studies. Volume 18 Issue 1. Pages $93-110$

- Smith S. L. J. (2010) Practical Tourism Research. London: CABI

- Smith M. (2007). Cultural Tourism in a Changing World. Tourism. The Journal for the Tourism Industry. The Tourism Society. Quarter 1 Issue 131. Pages 18 - 19

- Prendergast M. (2004) Theatre audience education or how to see a play: Toward a curriculum theory for spectatorship in the performing arts. Youth Theatre Journal. Volume 18 Issue 1. Pages 45 - 54

- Timothy J. (1998) Tourism and the Personal Heritage Experience. Annals of Tourism Research. Volume 24 Number 3. Pages 751 - 54

- Tooley J. (1999) In House-Covent Garden. 50 Years of Opera and Ballet. London: Faber and Faber

- Towse R. (2013) A Handbook of Cultural Economics. $2^{\text {nd }}$ Edition. Cheltenham: Edward Elgar Publishing 
- Urry J. (2002) The Tourist Gaze. Second Edition. London: SAGE

- Wing Tai Wai A. (2004) Place Promotion and Iconography in Shanghai's Xintiandi. Habitat International. Volume 30 Issue 2. Pages 245 - 260

- Waterton E., Smith L. and Campbell G. (2006) The utility of discourse analysis to heritage studies: The Burra Charter and social inclusion. International Journal of Heritage Studies. Volume 12 Issue 4. Pages 339 - 355

- Woolcock M. (2001) The Place of Social Capital in Understanding Social and Economic Outcomes”, in J.F. Helliwell (ed.) The Contri-bution of Human and Social Capital to Sustained Economic Growth and Well-being: International Symposium Report. Human Resources Development Canada and OECD

- Yin R.K. (2013) Case study research: Design and methods. $5^{\text {th }}$ Edition. London: SAGE 